Article

\title{
Minimum Energy Management Strategy of Equivalent Fuel Consumption of Hybrid Electric Vehicle Based on Improved Global Optimization Equivalent Factor
}

\author{
Xixue Liu, Datong Qin * and Shaoqian Wang \\ State Key Laboratory of Mechanical Transmissions, School of Automotive Engineering, Chongqing University, \\ Chongqing 400044, China; 13320239340@163.com (X.L.); wangshaoqian1996@163.com (S.W.) \\ * Correspondence: dtqin@cqu.edu.cn; Tel.: +86-136-0833-9935
}

Received: 23 April 2019; Accepted: 28 May 2019; Published: 30 May 2019

check for updates

\begin{abstract}
A parallel hybrid electric vehicle (PHEV) is used to investigate the fuel economy effect of the equivalent fuel consumption minimization strategy (ECMS) with the equivalent factor as the core, where the equivalent factor is the conversion coefficient between fuel thermal energy and electric energy. In the conventional ECMS strategy, the battery cannot continue to discharge when the state of charge (SOC) is lower than the target value. At this time, the motor mainly works in the battery charging mode, making it difficult to adjust the engine operating point to the high-efficiency zone during the acceleration process. To address this problem, a relationship model of the battery SOC, vehicle acceleration $a$, and equivalent factor $S$ was established. When the battery SOC is lower than the target value and the vehicle demand torque is high, which makes the engine operating point deviate from the high-efficiency zone, the time that the motor spends in the power generation mode during the driving process is reduced. This enables the motor to drive the vehicle at the appropriate time to reduce the engine output torque, and helps the engine operate in the high-efficiency zone. The correction function under US06 condition was optimized by genetic algorithm (GA). The best equivalent factor MAP was obtained with acceleration $a$ and battery SOC as independent variables, and the improved global optimal equivalent factor of ECMS was established and simulated offline. Simulation results show that compared with conventional ECMS, the battery still has positive power output even when the SOC is less than the target value. The SOC is close to the target value after the cycle condition, and fuel economy improved by $1.88 \%$; compared with the rule-based energy management control strategies, fuel economy improved by $10.17 \%$. These results indicate the effectiveness of the proposed energy management strategy.
\end{abstract}

Keywords: parallel hybrid electric vehicle; equivalent factor; state of charge; acceleration; genetic algorithm

\section{Introduction}

Hybrid electric vehicles (HEVs) have two major technical problems: mode switching during dynamic operation and energy distribution during steady-state operation [1]. Currently, energy management control strategies mainly fall into two categories: rule-based (RB) energy management and optimization-based control strategies [2]. Commonly used RB strategies include the charge-depleting and charge-sustaining (CD-CS) strategy and fuzzy logic (FL) rule-based strategy [3,4]. This kind of strategy is simple, easy to implement, and highly practical, but requires a wealth of prior knowledge and engineering experience. Global optimization-based control strategies under known working conditions include dynamic programming (DP) [5], Pontryagin's minimum 
principle (PMP) [6]. However, the calculations under this kind of strategy are not conducive to real-time optimization. The equivalent fuel consumption minimization strategy (ECMS) based on PMP uses the local optimum to replace the global optimum of the whole operating condition to achieve real-time optimization [7]. ECMS was first proposed by Paganelli and applied to hybrid vehicle energy management strategies; to minimize the instantaneous fuel consumption, the concept of the equivalent factor was introduced [8]. In [9], a real-time strategy based on Model Predictive Control (MPC) was proposed and applied to smart residential for the energy scheduling between renewable energy and an electrical energy storage system. The control strategy relies on an iterative finite horizon on-line optimization, implementing a quadratic cost function to minimize the electricity bill. This method was used to regulate the utilization between the two energy sources and was similar to the equivalent factor. However, the determination of the equivalent factor value does not guarantee that the battery SOC is maintained near the target value. Thus in $[10,11]$, a global optimization model of the equivalent factor was developed by considering the relationship between the battery SOC, equivalent fuel consumption, and the equivalent factor. A genetic algorithm was used to optimize the equivalent factor $S$ under given conditions, and the optimal equivalent factor MAP under different driving mileage and initial values of battery SOC were obtained. In [12], the charge-discharge equivalent factor was obtained according to the conversion relationship between fuel thermal energy and electric energy under cyclic conditions, and to keep the battery SOC within target value, the equivalent factor was modified by constructing an S-type correction function with SOC as an independent variable. The improved real-time equivalent energy minimum control strategy obtains the optimal torque distribution of the engine and motor under different initial SOCs on the premise of satisfying the power requirements of the vehicle. To improve the vehicle fuel economy, Shi et al. [13] presented a novel double-loop multi-objective particle swarm optimization algorithm to optimize the charging and discharging equivalent factor, but to maintain battery SOC balance, a correction function with SOC as an independent variable was established. Due to complex driving conditions in cities, Lin et al. [14] combined with the idea of ECMS and proposed an adaptive real-time optimization control strategy. In order to keep battery SOC within the target value, a PI (Proportional and Integral) penalty function with battery SOC as an independent variable was established. For non-plug in HEVs, their batteries mainly act as buffers. It can be seen from the reference $[8,10-14]$, in order to maintain the balance of HEV battery power, a correction function based on SOC as an independent variable has been established to avoid excessive battery discharge. However, the effect of acceleration $a$ on the equivalent factor has not been considered in the current articles.

According to the experimental data in [15], acceleration conditions only account for $30.79 \%$ of vehicles' operation time, while the corresponding fuel consumption accounts for $58.91 \%$ of the total fuel consumption over all driving conditions. The reasons for the increase in fuel consumption are as follows: (1) the increase in power demand of the whole vehicle; and (2) the shifting of the engine operating point from the best economic zone to the low-efficiency zone. The minimum instantaneous fuel consumption is not equivalent to the global minimum fuel consumption. To maintain the battery power close to the target value, the conventional correction function only considers the battery SOC, and does not continue to use the energy when the battery SOC approaches $\mathrm{SOC}_{\text {low }}$. At this time, the engine drives the motor to charge the battery until the SOC reaches the target value, after which the vehicle operates in the charge-sustaining (CS) mode. According to the existing literature [12-14,16], the lower limit of the SOC set for the power-maintaining hybrid vehicle battery ranges between 0.5 and 0.6 , but there is still room for continued use of electric energy. According to the statistical histogram of the acceleration of the vehicle driving condition in ADVISOR 2002, the time the vehicle spends at high acceleration is relatively short; hence, it will not cause the battery SOC to significantly decrease. When the vehicle acceleration is low or decelerating, engine-driven charging or regenerative braking can replenish the electricity consumed over time. Based on the equivalent factor correction function established by previous studies, a model of relationship between the battery SOC, vehicle acceleration $a$, and equivalent factor $\mathrm{S}$ is constructed in this paper. When the battery SOC is lower than the target 
value and the vehicle torque demand is large, the motor timely participates in the driving to adjust the engine operating point to ensure that the engine does not deviate from the working high-efficiency zone to further improve the fuel economy of the vehicle.

\section{Vehicle Dynamical Systems Structure and Modeling}

The structure and parameters of the integrated starter-generator (ISG) hybrid vehicle studied in this paper are shown in Figure 1 and Table 1. The main components of the system include the engine, wet multi-plate clutch C1, ISG, continuously variable transmission (CVT), final drive, battery pack, etc. The vehicle control unit (VCU) starts the engine and switches between the pure electric drive and hybrid drive of the vehicle by controlling the combination and separation of the wet multi-plate clutch C1.

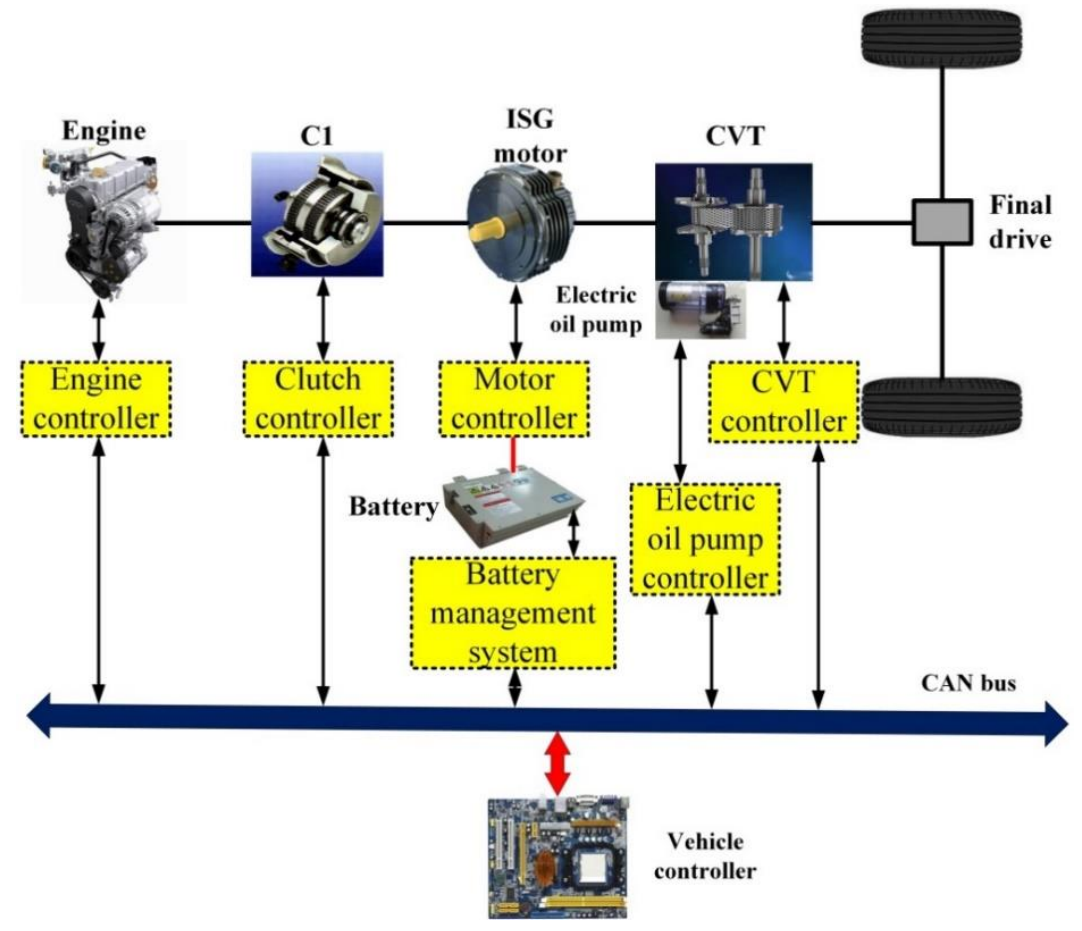

Figure 1. Structure of vehicle transmission system.

Table 1. HEV parameters.

\begin{tabular}{ccc}
\hline Components & Parameter and Units & Values \\
\hline \multirow{3}{*}{ Vehicle } & Mass $m / \mathrm{kg}$ & 1547 \\
& Frontal area $A / \mathrm{m}^{2}$ & 2.28 \\
& Wind resistance coefficient $C_{D}$ & 0.357 \\
& Wheel radius $r / \mathrm{m}$ & 0.289 \\
Engine & Rolling drag coefficient $f$ & 0.0083 \\
& Maximum power $P_{\text {emax }} / \mathrm{kW}$ & 90 \\
& Maximum torque $T_{\text {emax }} / \mathrm{Nm}$ & $160 / 3900 \mathrm{rpm}$ \\
ISG motor & Maximum power $P_{\max } / \mathrm{kW}$ & 32 \\
& Maximum torque $T_{\max } / \mathrm{Nm}$ & 113 \\
& Range of rotation $\omega_{m} \mathrm{rpm}$ & $0-6000$ \\
Battery & Capacity $Q_{0} /(\mathrm{A} \cdot \mathrm{h})$ & 40 \\
& Rated voltage $U_{0} / \mathrm{V}$ & 352 \\
& Speed ratio range $i_{c v t}$ & $0.422-2.432$ \\
& Final drive ratio $i_{0}$ & 5.297 \\
\hline
\end{tabular}




\subsection{Vehicle Longitudinal Dynamics Model}

According to the vehicle configuration in this study, the vehicle torque and speed must always meet the following conditions at any time in hybrid drive mode:

$$
\begin{gathered}
T_{r e q}(t)=\left(T_{e}(t) \pm T_{m}(t)\right) i_{c v t}(t) i_{0} \eta_{T}(t) \\
\omega_{m}(t)=\omega_{e}(t)=\omega_{w}(t) i_{c v t}(t) i_{0} \\
u(t)=0.377 \frac{\omega_{w}(t) r}{i_{c v t}(t) i_{0}}
\end{gathered}
$$

\begin{tabular}{|c|c|c|c|}
\hline Variable & Meaning (Units) & Variable & Meaning (Units) \\
\hline$T_{r e q}(t)^{1}$ & vehicle demand torque $(\mathrm{Nm})$ & $\omega_{m}(t)^{1}$ & motor speed (rpm) \\
\hline$T_{e}(t)^{1}$ & engine torque $(\mathrm{Nm})$ & $\omega_{e}(t)^{1}$ & engine speed (rpm) \\
\hline$T_{m}(t)^{1}$ & motor torque (Nm) & $\omega_{w}(t)^{1}$ & wheel speed (rpm) \\
\hline$i_{c v t}(t)^{1}$ & CVT speed ratio & $u(t)^{1}$ & vehicle speed $(\mathrm{Km} / \mathrm{h})$ \\
\hline$i_{0}$ & the final drive ratio & $r$ & wheel radius (m) \\
\hline$\eta_{T}(t)^{1}$ & $\begin{array}{l}\text { the efficiency of the } \\
\text { transmission system }\end{array}$ & - & - \\
\hline
\end{tabular}

The meanings of the variables in Formulas (1)-(3) are shown in Table 2.

Table 2. Vehicle longitudinal dynamics model variables.

\subsection{Engine and Motor Model}

The establishment of engine and motor models mainly includes theoretical modeling and experimental modeling. Considering the complexity of theoretical modeling, this study chose a numerical model. Based on experimental data, a three-dimensional map was created by interpolation of the data and the data required for the engine and motor obtained by looking it up in the table.

$$
\begin{gathered}
b e(t)=b e\left(\omega_{e}(t), T_{e}(t)\right) \\
\eta_{e}(t)=\eta_{e}\left(\omega_{e}(t), T_{e}(t)\right) \\
V_{f u e l}(t)=\frac{1}{3.6 \times 10^{6}} \int_{0}^{t_{f}} P_{e}(t) b_{e}(t) d t \\
\eta_{m \_c h g}(t)=\eta_{m \_c h g}\left(\omega_{m}(t), T_{m \_c h g}(t)\right) \\
\eta_{m \_d i s}(t)=\eta_{m \_d i s}\left(\omega_{m}(t), T_{m \_d i s}(t)\right)
\end{gathered}
$$

\begin{tabular}{|c|c|c|c|}
\hline Variable & Meaning (Units) & Variable & Meaning (Units) \\
\hline$b e(t)^{1}$ & the engine fuel consumption rate $(\mathrm{g} / \mathrm{kW} \cdot \mathrm{h})$ & $\eta_{m \_c h g}(t)^{1}$ & $\begin{array}{l}\text { efficiency of the motor during power } \\
\text { generation }\end{array}$ \\
\hline$\eta_{e}(t)^{1}$ & the engine efficiency & $\eta_{m \_d i s}(t)^{1}$ & efficiency of the motor during driving \\
\hline$V_{\text {fuel }}(t)^{1}$ & the engine fuel consumption (L) & $T_{m_{-} \text {chg }}(t)^{1}$ & $\begin{array}{l}\text { torque of the motor during power } \\
\text { generation }(\mathrm{Nm})\end{array}$ \\
\hline 0 and $t_{f}$ & $\begin{array}{l}\text { the initial and end time of engine } \\
\text { operation (s) }\end{array}$ & $T_{m \_d i s}(t)^{1}$ & $\begin{array}{l}\text { torque of the motor during driving } \\
\qquad(\mathrm{Nm})\end{array}$ \\
\hline$P e(t)^{1}$ & engine power $(\mathrm{kW})$ & - & - \\
\hline
\end{tabular}

The meanings of the variables in Formulas (4)-(8) are shown in Table 3.

Table 3. Engine and motor model variables. 


\subsection{Battery Model}

The battery model includes an internal resistance model and a capacity resistance model. In this study, the more commonly used internal resistance model was selected. The SOC change and charging and discharging efficiency of the battery can be expressed by Equations (9)-(11). Assuming that the storage energy degradation and leakage effects are negligible [9,17]:

$$
\begin{gathered}
\dot{S O C}(t)=-\frac{V_{o c}(s o c)-\sqrt{V_{o c}^{2}(s o c)-4 R_{b}(s o c) P_{b}(t)}}{2 R_{b}(s o c) Q_{0}} \\
\eta_{b \_c h g}(t)=\frac{\left(V_{o c}(s o c)-\sqrt{V_{o c}^{2}(s o c)-4 R_{b}(s o c) P_{b}(t)}\right) V_{o c}(s o c)}{2 R_{b}(s o c) P_{b}(t)} \\
\eta_{b \_d i s}(t)=\frac{2 R_{b}(s o c) P_{b}(t)}{\left(V_{o c}(s o c)-\sqrt{V_{o c}^{2}(s o c)-4 R_{b}(s o c) P_{b}(t)}\right) V_{o c}(s o c)} \\
P_{b}(t)= \begin{cases}\frac{T_{\mathrm{m}}(t) \omega_{m}(t)}{9550 \eta_{m}-d i s}(t) & P_{\mathrm{m}} \geq 0 \\
\frac{T_{\mathrm{m}}(t) \omega_{m}(t) \eta_{m \_c h g}(t)}{9550} & P_{m}<0\end{cases}
\end{gathered}
$$

The meanings of the variables in Formulas (9)-(12) are shown in Table 4.

Table 4. Battery model variables.

\begin{tabular}{cccc}
\hline Variable & Meaning (Units) & Variable & Meaning (Units) \\
\hline$\dot{B} C(t)^{1}$ & SOC change of the battery & $\eta_{b_{-} c h g}(t)^{1}$ & the battery charge efficiency \\
$Q_{0}$ & the capacitance of the battery $(\mathrm{Ah})$ & $\eta_{b_{-} d i s}(t)^{1}$ & the battery discharge efficiency \\
$V_{o c}(s o c)^{2}$ & the battery open circuit voltage $(\mathrm{V})$ & $P_{b}(t)^{1}$ & the power of the battery $(\mathrm{kW})$ \\
$R_{b}(s o c)^{2}$ & the battery internal resistance $(\Omega)$ & $P_{m}(t)^{1}$ & the power of the motor $(\mathrm{kW})$ \\
\hline
\end{tabular}

${ }^{1}$ are the values of variables at time $t$ and they are all functions of time. ${ }^{2}$ are the values of variables under different battery SOC and they are all functions of SOC.

For the power retention type HEV, the battery SOC should be kept in the middle range, and it is possible to receive the regenerative braking energy while ensuring sufficient power to provide traction, which helps improve the battery life $[18,19]$.

\subsection{CVT Model}

CVT has the characteristics of a continuous change of speed ratio. When the engine participates in the whole vehicle drive, the engine operating point can be changed by continuously adjusting the speed ratio to make it work in the high efficiency range as much as possible. The acquisition of the CVT ratio can be optimally obtained by the instantaneous efficiency of the vehicle under different demand torque and vehicle speed. CVT transmission efficiency is a function of the speed ratio and the torque, which can be obtained by looking them up the table:

$$
\eta_{c v t}(t)=\eta_{c o t}\left(i_{c v t}(t), T_{c v t}(t)\right)
$$

The meanings of the variables in Formula (13) are shown in Table 5.

Table 5. CVT model variables.

\begin{tabular}{cccc}
\hline Variable & Meaning (Units) & Variable & Meaning (Units) \\
\hline$\eta_{\text {cvt }}(t)^{1}$ & the efficiency of CVT & $T_{\text {cvt }}(t)^{1}$ & CVT transmission torque (Nm) \\
\hline & 1 are the values of variables at time $t$ and they are all functions of time.
\end{tabular}


Figure 2 shows the CVT speed ratio in the hybrid drive mode, the engine individual drive mode, the motor individual drive mode, and the regenerative brake mode, which are obtained by instantaneous optimization efficiency.
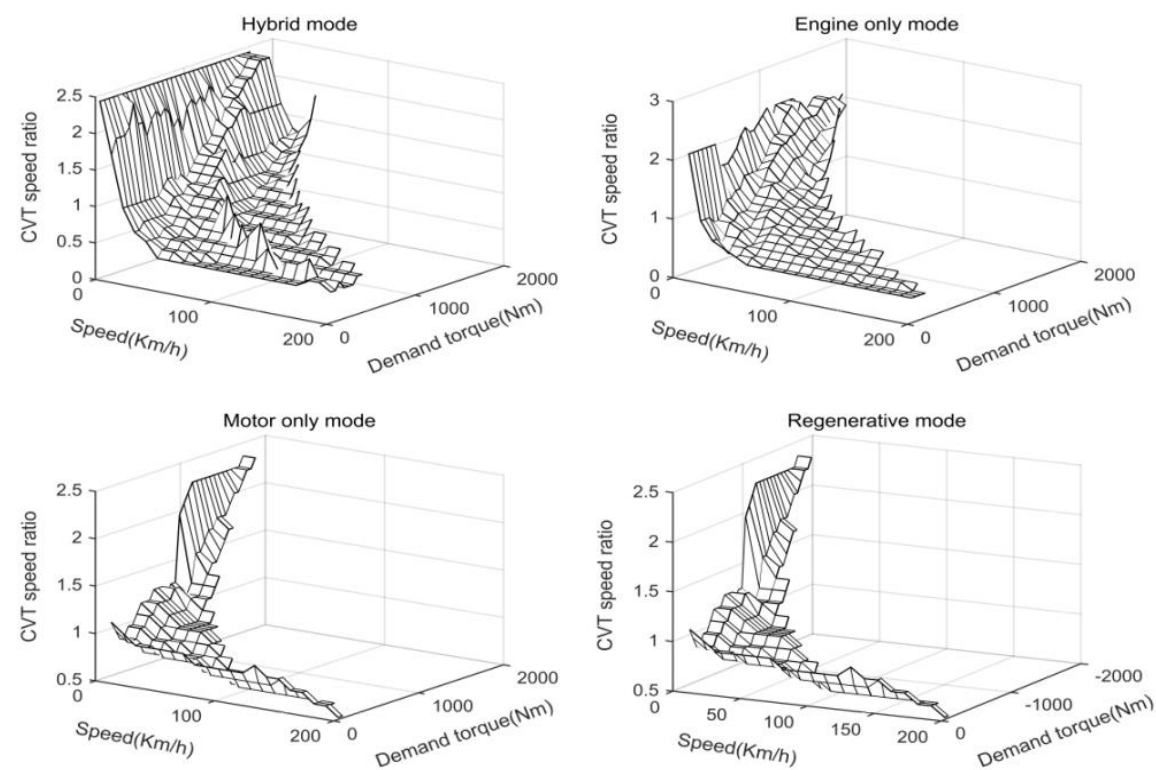

Figure 2. CVT optimal speed ratio in each mode.

\section{Conventional ECMS Model}

\subsection{Build ECMS Optimization Objective Functions}

The minimum equivalent fuel consumption was achieved by reasonably considering the cost of engine power generation and the loss of motor operation. The power consumption and fuel consumption should be treated equivalently, so that the overall fuel consumption is greatly reduced [20].

The vehicle's total fuel consumption objective function is:

$$
\left\{\begin{array}{l}
Q_{E C M S}(t)=\sum_{0}^{t v} J_{E C M S} \\
J_{E C M S}=\dot{m}_{\text {eng }}\left(P_{e}(t)\right)+S_{\text {equ }}\left(P_{b}(t)\right)
\end{array}\right.
$$

$S_{\text {equ }}\left(P_{b}(t)\right)$ is the battery equivalent fuel consumption and can be expressed by Equation (15):

$$
S_{\text {equ }}\left(P_{b}(t)\right)= \begin{cases}s_{\text {equ }}(t) \frac{P_{b}(t)}{\eta_{\text {dis }}(t) Q_{f}} & P_{b}(t)>0 \\ 0 & P_{b}(t)=0 \\ s_{\text {equ }}(t) \frac{P_{b}(t)}{Q_{f}} \eta_{\text {chg }}(t) & P_{b}(t)<0\end{cases}
$$

$s_{\text {equ }}(t)$ is the equivalent factor and can be expressed as:

$$
s_{\text {equ }}(t)= \begin{cases}s_{\text {dis }}=\frac{1}{\bar{\eta}_{e} \bar{\eta}_{\eta_{\text {_chg }}} \bar{\eta}_{\text {chg }}} & P_{b} \geq 0 \\ s_{\text {chg }}=\frac{\bar{\eta}_{m_{\text {_dis }}} \bar{\eta}_{\text {dis }}}{\bar{\eta}_{e}} & P_{b}<0\end{cases}
$$

The meanings of the variables in Formulas (14)-(16) are shown in Table 6. 
Table 6. Conventional ECMS model variables.

\begin{tabular}{|c|c|c|c|}
\hline Variable & Meaning (Units) & Variable & Meaning (Units) \\
\hline$Q_{E C M S}(t)^{1}$ & the total equivalent fuel consumption (L) & $\bar{\eta}_{m \_c h g}$ & $\begin{array}{l}\text { average efficiency of the motor during } \\
\text { power generation }\end{array}$ \\
\hline$J_{E C M S}$ & $\begin{array}{l}\text { instantaneous equivalent fuel } \\
\text { consumption (L) }\end{array}$ & $\bar{\eta}_{e}$ & average engine efficiency \\
\hline 0 and $t_{v}$ & $\begin{array}{l}\text { the initial and end time of the vehicle } \\
\text { operation (s) }\end{array}$ & $Q_{f}$ & the low calorific value of the fuel \\
\hline$\dot{m}_{\text {eng }}\left(P_{e}(t)\right)^{1}$ & $\begin{array}{l}\text { the engine instantaneous fuel } \\
\text { consumption }(\mathrm{L})\end{array}$ & SO & the battery SOC after normalization \\
\hline$S_{e q u}\left(P_{b}(t)\right)^{1}$ & $\begin{array}{l}\text { the battery instantaneous equivalent fuel } \\
\text { consumption (L) }\end{array}$ & $S O C_{u p}$ & $\begin{array}{l}\text { the upper limit of the battery } \\
\text { during operation }\end{array}$ \\
\hline$S_{\text {equ }}(t)^{1}$ & battery equivalent factor & $\mathrm{SOC}_{l}$ & $\begin{array}{l}\text { the lower limit of the battery } \\
\text { during operation }\end{array}$ \\
\hline $\bar{\eta}_{c h g}$ & $\begin{array}{l}\text { average charge efficiency of the battery } \\
\text { average discharge efficiency of the battery }\end{array}$ & $\begin{array}{c}P(S O) \\
m \text { and } n\end{array}$ & $\begin{array}{l}\text { the correction factor of the battery SOC } \\
\text { SOC correction function coefficients }\end{array}$ \\
\hline $\bar{\eta}_{m \_d i s}$ & $\begin{array}{c}\text { average efficiency of the motor } \\
\text { during driving }\end{array}$ & $S_{\text {dis }}(t), S_{\text {chg }}(t)^{1}$ & $\begin{array}{l}\text { the discharge and charge equivalent factors } \\
\text { of the battery }\end{array}$ \\
\hline
\end{tabular}

\subsection{Correction Function with SOC as Independent Variable}

In order to ensure that the SOC of the battery is maintained within the target range, an S-type correction function was proposed [21] to modify the equivalent fuel consumption of the battery by changing the equivalent factor value to regulate the power distribution between the engine and motor. When the SOC is high, the equivalent factor value decreases along with the cost of electric energy relative to the fuel; hence, the vehicle tends to use electric energy; When the SOC is low, the equivalent factor value increases along with the cost of the electric energy relative to the fuel; hence, the vehicle tends to consume fuel.

From the relationship between the SOC and internal resistance of the battery in Figure 3 and the literature $[18,19]$, the operating range of the battery SOC was set between 0.5 and 0.8 . It is desirable that the SOC of the battery be maintained at approximately 0.65 . Before solving the expression, the battery SOC should first be standardized as shown in Equation (17):

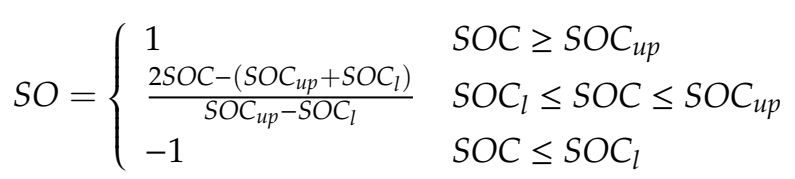

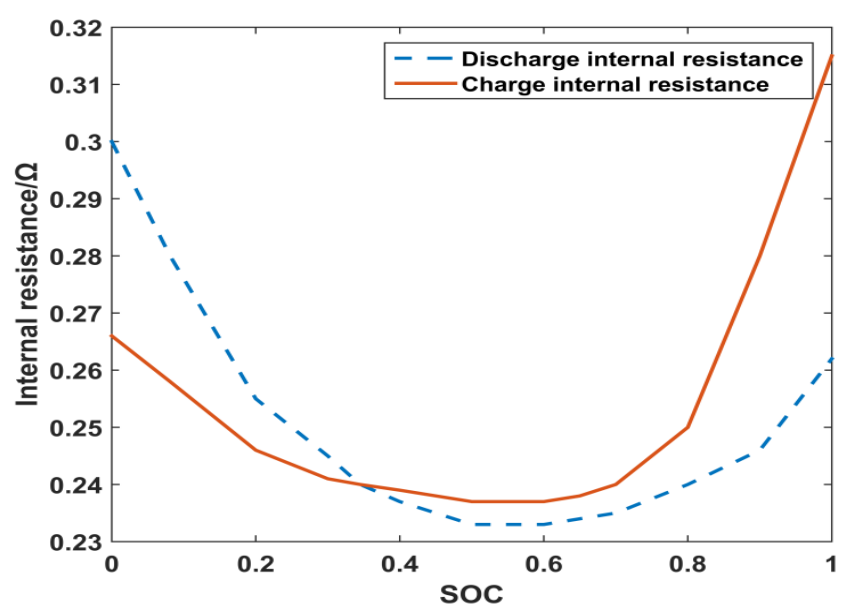

Figure 3. Relationship between battery SOC and resistance.

To maintain the SOC balance, the S-shaped correction function is as follows:

$$
P(S O)=1-m \times S O^{3}+n \times S O^{4}
$$


The meanings of the variables in Formulas (17)-(18) are shown in Table 6.

Figure 4 shows the SOC correction function at different coefficients. When the SOC is lower than the target value, different $\mathrm{m}, \mathrm{n}$ values have a greater influence on the equivalent factor value. The instantaneous equivalent minimum fuel consumption is sensitive to the equivalent factor [22]; hence, it is necessary to find the value of the best correction factor.

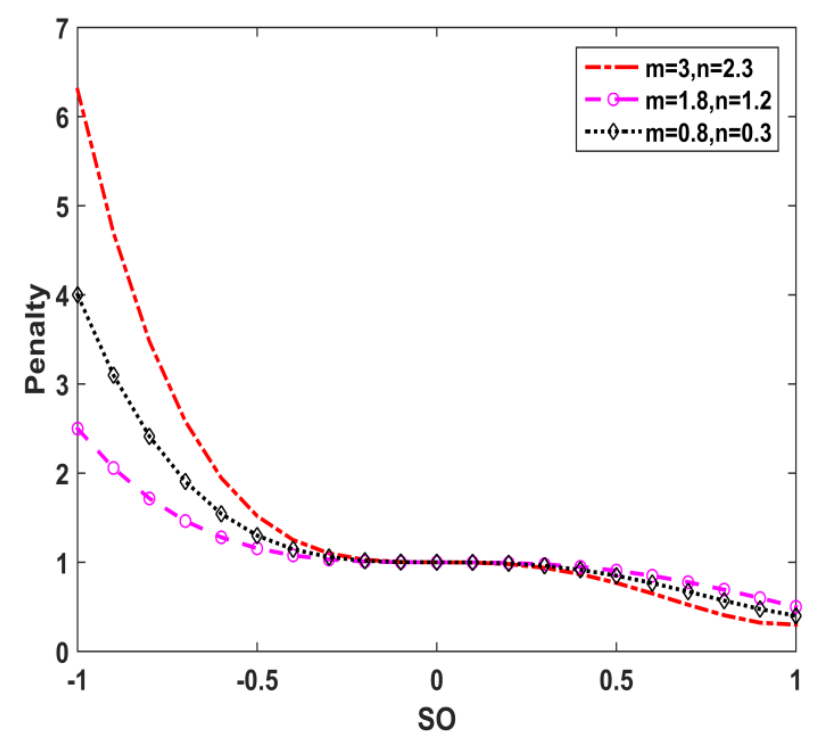

Figure 4. SOC correction function under different coefficients.

\section{Improved ECMS Model}

\subsection{Correction Function with Acceleration a as the Independent Variable}

During the driving process, when the vehicle acceleration is large and the SOC of the battery is less than $S O C_{\text {low }}$, the conventional ECMS control strategy will increase the value of the equivalent factor. At this time, the battery switches from the discharge state to the fast charge state, and the engine load is greatly increased, which in turn causes the engine operating point to deviate from the high-efficiency zone. Therefore, to reduce the engine fuel consumption rate when the vehicle acceleration is high and SOC is low, the equivalent factor should be appropriately reduced, and the torque output of the motor is increased to compensate for the increased external demand torque, thereby reducing the fuel consumption of the vehicle.

From the driving conditions of the vehicle, the acceleration under four representative working conditions: NEDC, UDDS, HWFET, and US06 were selected for analysis. Figure 5 shows that the acceleration range of the US06 operating condition is larger, and the range is between $-3.5 \mathrm{~m} / \mathrm{s}^{2}$ and $4 \mathrm{~m} / \mathrm{s}^{2}$, while that of the other three operating conditions range between $-1.5 \mathrm{~m} / \mathrm{s}^{2}$ and $1.5 \mathrm{~m} / \mathrm{s}^{2}$. 

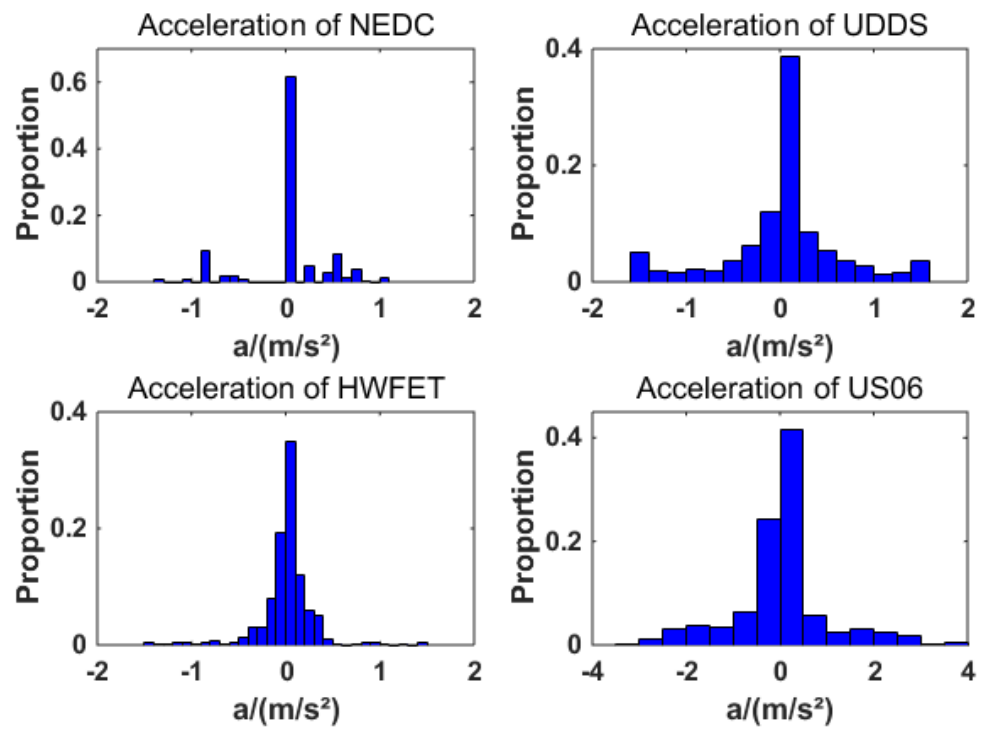

Figure 5. Four working condition acceleration values.

Before solving the expression, the acceleration was also standardized by the same method shown in Equation (19):

$$
a a= \begin{cases}1 & a \geq a_{u p} \\ \frac{2 a}{a_{u p}-a_{l}} & a_{l}<a<a_{u p} \\ -1 & a \leq a_{l}\end{cases}
$$

According to the range of acceleration values under typical working conditions, the upper and lower limits of acceleration $a_{u p}$ and $a_{l}$ are set to $1.5 \mathrm{~m} / \mathrm{s}^{2}$ and $-1.5 \mathrm{~m} / \mathrm{s}^{2}$, respectively.

The parabolic correction function is written as:

$$
P(a a)= \begin{cases}1-\delta a a^{3}+\gamma a a^{4} & 0 \leq a a \leq 1 \\ 1 & -1 \leq a a \leq 0\end{cases}
$$

The meanings of the variables in Formulas (19)-(20) are shown in Table 7.

\begin{tabular}{|c|c|c|c|}
\hline Variable & Meaning (Units) & Variable & Meaning (Units) \\
\hline$a a$ & $\begin{array}{l}\text { the acceleration after } \\
\text { normalization }\left(\mathrm{m} / \mathrm{s}^{2}\right)\end{array}$ & $\omega_{\max }$ & $\begin{array}{l}\text { the maximum rotating speed of the } \\
\text { motor (rpm) }\end{array}$ \\
\hline$a_{u p}$ & The upper limit of acceleration $\left(\mathrm{m} / \mathrm{s}^{2}\right)$ & $T_{e \min }\left(\omega_{e}(t)\right)^{1}$ & $\begin{array}{l}\text { the minimum torque of the engine } \\
\text { when the rotating speed is } \omega_{e}(t)(\mathrm{Nm})\end{array}$ \\
\hline$a_{l}$ & the lower limit of acceleration $\left(\mathrm{m} / \mathrm{s}^{2}\right)$ & $T_{e \max }\left(\omega_{e}(t)\right)^{1}$ & $\begin{array}{l}\text { the maximum torque of the engine } \\
\text { when the rotating speed is } \omega_{e}(t)(\mathrm{Nm})\end{array}$ \\
\hline$P(a a)$ & $\begin{array}{l}\text { correction factor of the } \\
\text { vehicle acceleration }\end{array}$ & $T_{m \min }\left(\omega_{m}(t)\right)^{1}$ & $\begin{array}{l}\text { the minimum torque of the motor } \\
\text { when the rotating speed is } \omega_{m}(t)(\mathrm{Nm})\end{array}$ \\
\hline$\delta, \gamma$ & $\begin{array}{l}\text { acceleration correction } \\
\text { function coefficients }\end{array}$ & $T_{m \max }\left(\omega_{m}(t)\right)^{1}$ & $\begin{array}{l}\text { the maximum torque of the motor } \\
\text { when the rotating speed is } \omega_{m}(t)(\mathrm{Nm})\end{array}$ \\
\hline$P(S O, a a)$ & $\begin{array}{c}\text { correction function with battery SOC } \\
\text { and vehicle acceleration } a \text { as } \\
\text { independent variables }\end{array}$ & $S O C_{o b j}$ & the target value of the battery SOC \\
\hline$P_{b r}(t)^{1}$ & regenerative braking energy (MJ) & $T_{e}^{o p t}(t)^{1}$ & $\begin{array}{l}\text { the optimal torque distribution of the } \\
\text { engine }(\mathrm{Nm})\end{array}$ \\
\hline$\omega_{e \min }(t), \omega_{e \max }(t)$ & $\begin{array}{l}\text { the minimum and maximum rotating } \\
\text { speed of the engine (rpm) }\end{array}$ & $T_{m}^{o p t}(t)^{1}$ & $\begin{array}{l}\text { the optimal torque distribution of the } \\
\text { motor }(\mathrm{Nm})\end{array}$ \\
\hline
\end{tabular}

Table 7. Improved ECMS model variables. 


\subsection{Optimal Equivalence Factor MAP Establishment}

Establishment of Equivalence Factor MAP with SOC and $a$ as Independent Variables

The final battery equivalent fuel consumption equation is:

$$
\left\{\begin{array}{l}
S_{\text {equ }}\left(P_{b}(t)\right)=P(S O, a a)\left[s_{\text {dis }} k \frac{P_{b}(t)+P_{b r}(t)}{\eta_{\text {dis }}(t)}+s_{\text {chg }}(1-k) P_{b}(t) \eta_{c h g}(t)\right] \\
P(S O, a a)=\left(1-m \times S O^{3}+n \times S O^{4}\right) \times\left(1-\delta \times a a^{3}+\gamma \times a a^{4}\right)
\end{array}\right.
$$

where $k(t)=1$ if $P_{b}(t)>0$ and $k(t)=0$ if $P_{b}(t)<0$.

The constraint ranges are:

$$
\left\{\begin{array}{l}
\omega_{e \min } \leq \omega_{e}(t) \leq \omega_{e \max } \\
0 \leq \omega_{m}(t) \leq \omega_{m \max } \\
T_{e \min }\left(\omega_{e}(t)\right) \leq T_{e}(t) \leq T_{e \max }\left(\omega_{e}(t)\right) \\
T_{m \min }\left(\omega_{m}(t)\right) \leq T_{m}(t) \leq T_{m \max }\left(\omega_{m}(t)\right) \\
S O C_{l} \leq S O C(t) \leq S O C_{u p} \\
S O C\left(t_{f}\right) \approx S O C_{o b j}
\end{array}\right.
$$

The meanings of the variables in Formulas (21)-(22) are shown in Table 7.

Problem (21) is a nonlinear optimization problem that consists in determining the two decision variables in $S O$, a a that minimize the objective function in (14) and meet the six bounding constraints, two equality constraints, and the decision variables are real. $P_{b r}(t)$ is "free energy" that needs to be removed when calculating the equivalent fuel consumption; According to the method of obtaining the equivalent factor in the literature [23], the simulation of the given cycle condition with different $u$ values can be used to determine the electrical energy and fuel energy consumption $\left[\mathrm{E}_{\mathrm{b}}(u), \mathrm{E}_{\mathrm{e}}(u)\right]$, as shown in Figure 6. The $u$ value represents the ratio of the engine fuel energy consumption to driving energy consumption of the vehicle. If $u>1$, then the engine drives the motor to generate electricity while driving the whole vehicle; if $u<1$, then the engine and motor jointly drive the whole vehicle; if $u=1$, then the vehicle is driven only by the engine and the corresponding abscissa is the regenerative braking energy under the whole cycle condition. The slopes at $u<1$ and $u>1$ represent the equivalent fuel consumption factors for battery charging and discharging, respectively. $m, n, \delta, \gamma$ are coefficients of the equivalent factor correction function, respectively, and each coefficient value range is set to $m, n, \delta, \gamma \in[0,2]$.

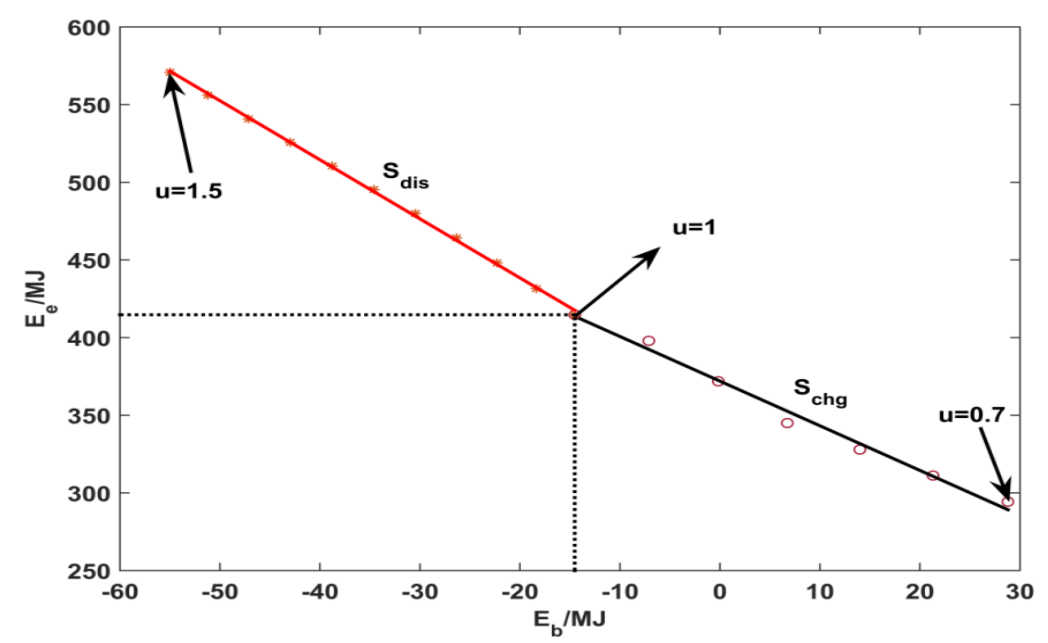

Figure 6. Equivalent relationship between fuel energy and electric energy. 
In this paper, a genetic algorithm (GA) and MatLab/Simulink were combined to solve the correction function coefficients. Figure 7 shows the optimization process of solving the equivalent factor correction function.

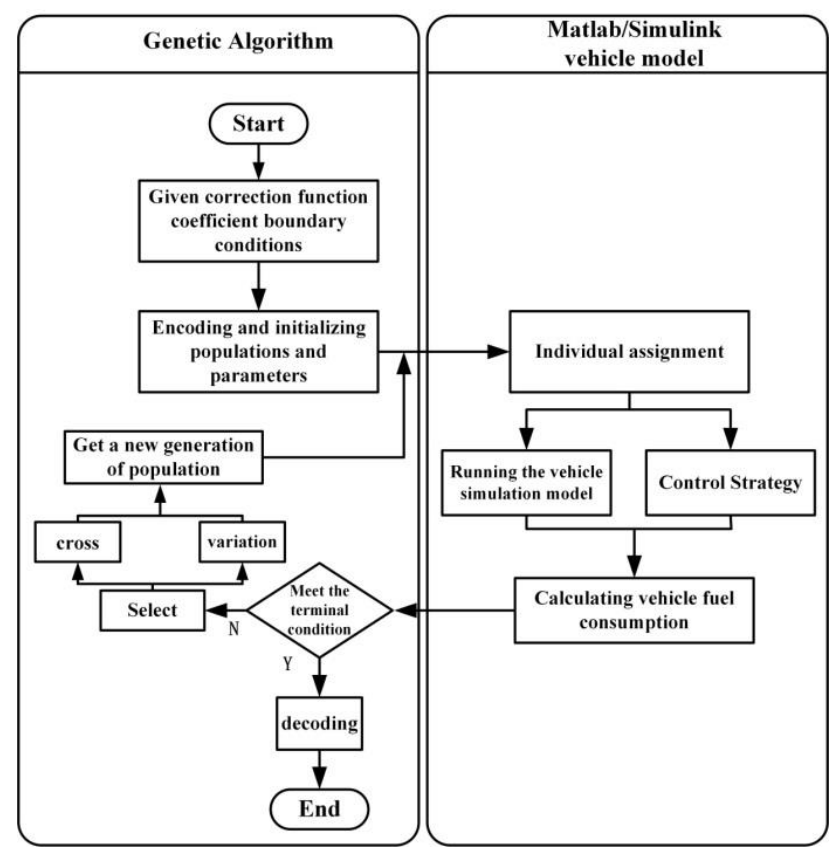

Figure 7. Global optimization model based on GA.

\subsection{Improved ECMS Real-Time Optimization Solution}

For a single-shaft parallel hybrid vehicle, the engine and motor are coaxially connected in parallel. The engine speed in the hybrid drive mode is not a controlled variable; thus, the torque becomes the only control variable of the energy management strategy. The power distribution at this time is equivalent to the torque distribution [24]. Therefore, the torque of the motor is used as the control variable.

Under the premise of driving and satisfying the dynamics of vehicle conditions, the torque of the motor was gradually increased from $T_{m \min }$ to $T_{m \text { max }}$. The corresponding engine torque value at this time is $\min \left[\left(T_{r e q}-T_{m \min }\right), T_{e \max }\right] \sim \max \left[\left(T_{r e q}-T_{m \max }\right), T_{e \min }\right]$. The engine and motor power were obtained according to the engine and motor speed, and the equivalent fuel consumption rate of the engine and battery was calculated by the fuel consumption model. The function:

$$
\left\{T_{e}^{o p t}(t), T_{m}^{o p t}(t)\right\}=\arg \min _{\left\{T_{e}(t), T_{m}(t)\right\}} Q(t)
$$

to be optimized was used to solve the torque corresponding to the engine and motor at this time. $T_{e}^{o p t}(t), T_{m}^{o p t}(t)$ constraint ranges are:

$$
\left\{\begin{array}{l}
T_{e \min }\left(\omega_{e}(t)\right) \leq T_{e}^{o p t}(t) \leq T_{e \max }\left(\omega_{e}(t)\right) \\
T_{m \min }\left(\omega_{m}(t)\right) \leq T_{m}^{o p t}(t) \leq T_{m \max }\left(\omega_{m}(t)\right)
\end{array}\right.
$$

The meanings of the variables in formulas (23)-(24) are shown in Table 7.

The solution process is shown in Figure 8. 


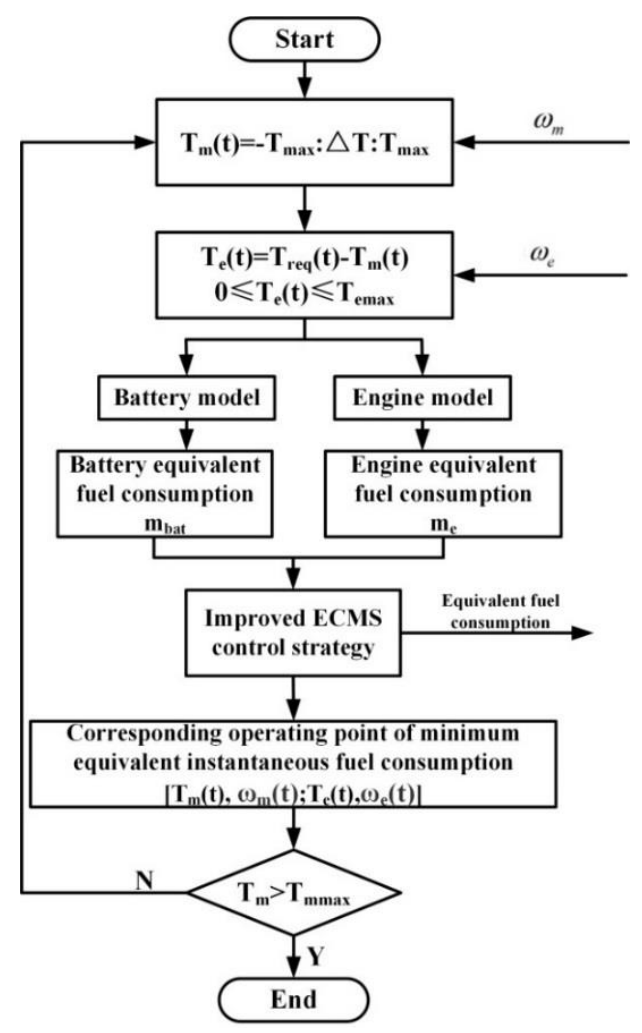

Figure 8. Improved ECMS solution flow chart.

\section{Simulation and Analysis}

\subsection{GA Optimization Result}

In this study, the 10-US06 operating condition with large acceleration and acceleration time ratios were selected to verify the effectiveness of the new control strategy. The total mileage is $128.1 \mathrm{~km}$, and the initial SOC is 0.5 . The population evolutionary algebra is 150; the population size is 50; the progeny crossover probability is 0.8 , and the mutation probability is 0.02 . Table 8 lists the optimal correction function coefficients after GA optimization. Figure 9 shows the optimal correction factors MAP with different accelerations and SOCs after GA optimization.

Table 8. Optimal correction function coefficient.

\begin{tabular}{ccccc}
\hline Coefficient & $m$ & $n$ & $\delta$ & $\gamma$ \\
\hline Values & 0.1577 & 0.015 & 1.38 & 1.035 \\
\hline
\end{tabular}




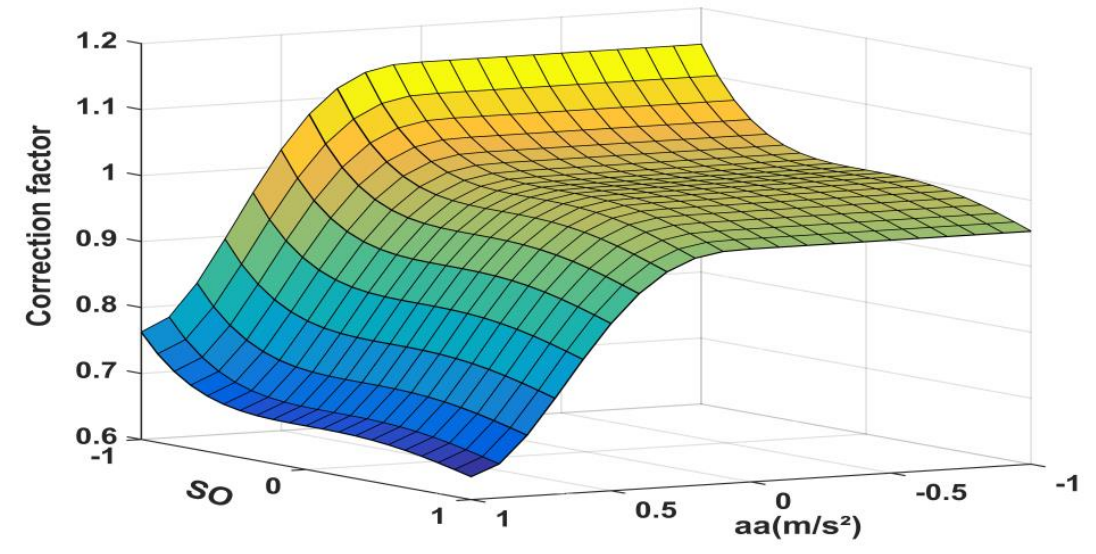

Figure 9. Optimal correction factor MAP with different accelerations and SOCs.

Through offline global optimization, the optimal correction factor corresponding to the lowest running cost of the whole vehicle under different accelerations and battery SOCs was obtained. When the acceleration of the whole vehicle is large and the SOC of the battery is lower than the target value, the value of the correction factor is less than 1 , which indicates that the cost of electricity is lower than that of fuel at this time, and the battery can still discharge and drive the motor to operate. When the acceleration is small and the battery SOC is too low, the correction factor value is greater than 1 , which indicates that the cost of electricity is higher than that of fuel, and the engine should drive the motor to charge the battery.

\subsection{Vehicle Simulation Results and Analysis}

In order to verify the fuel-saving effect of improved ECMS and battery SOC retention, the numerical model of the whole vehicle components and the improved ECMS strategy model was established based on the MatLab/Simulink platform, and the backward simulation model of vehicle dynamics was developed. The improved ECMS, conventional ECMS, and RB energy management control strategies were compared under 10-US06 condition with initial battery SOC of 0.5. Figure 10 shows the working condition of US06. It can be seen from the figure that the vehicle has large acceleration and deceleration under all working conditions.

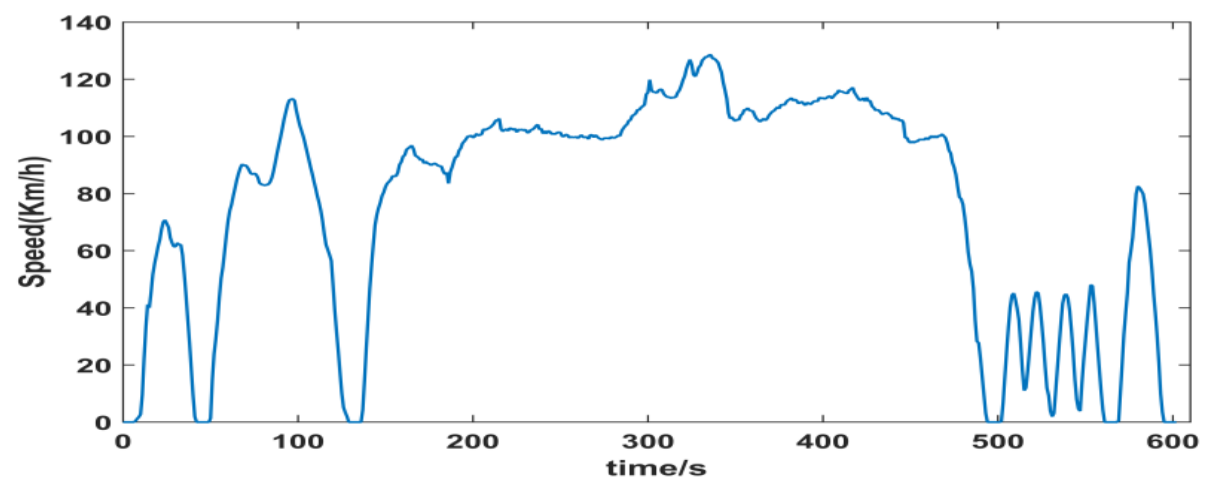

Figure 10. US06 condition.

Figure 11 shows the SOC variations under the improved ECMS and conventional ECMS. The equivalent factor of the conventional ECMS only depends on the battery SOC. When the SOC is lower than the target value, the battery is in the charging mode most of the time; hence, the battery SOC rises rapidly in the initial stage, and the vehicle operates in the CS mode when the SOC target value is reached. The equivalent factor of the improved ECMS is determined by the battery SOC and 
vehicle acceleration $a$. When the SOC is lower than the target value but the vehicle acceleration is very large, the value of the equivalent factor will be reduced and the battery still has positive power output drive the motor to assist the engine. When the demand torque is small, the engine appropriately increases the torque output to drive the motor to charge the battery. Therefore, the improved ECMS gradually increases the battery SOC, which eventually remains close to the target value throughout the cycle. Figure 12 shows the comparison of the engine and motor torque changes under the first three cycle conditions. When the SOC is lower than the target value, for the conventional ECMS, the engine drives the motor to charge the battery while driving the whole vehicle; thus, the output torque is very large. For the improved ECMS, when the vehicle acceleration or vehicle demand is very large, the motor still has positive power output or does not act as generator to charge the battery, which prevents the reduction of the fuel economy of the vehicle owing to the large output torque of the engine. When the torque demand or acceleration of the whole vehicle is small, the value of the equivalent factor will increase and the engine appropriately increases the output torque to drive the motor and charge the battery to avoid the SOC from becoming too low; the engine operating point efficiency can also be improved.

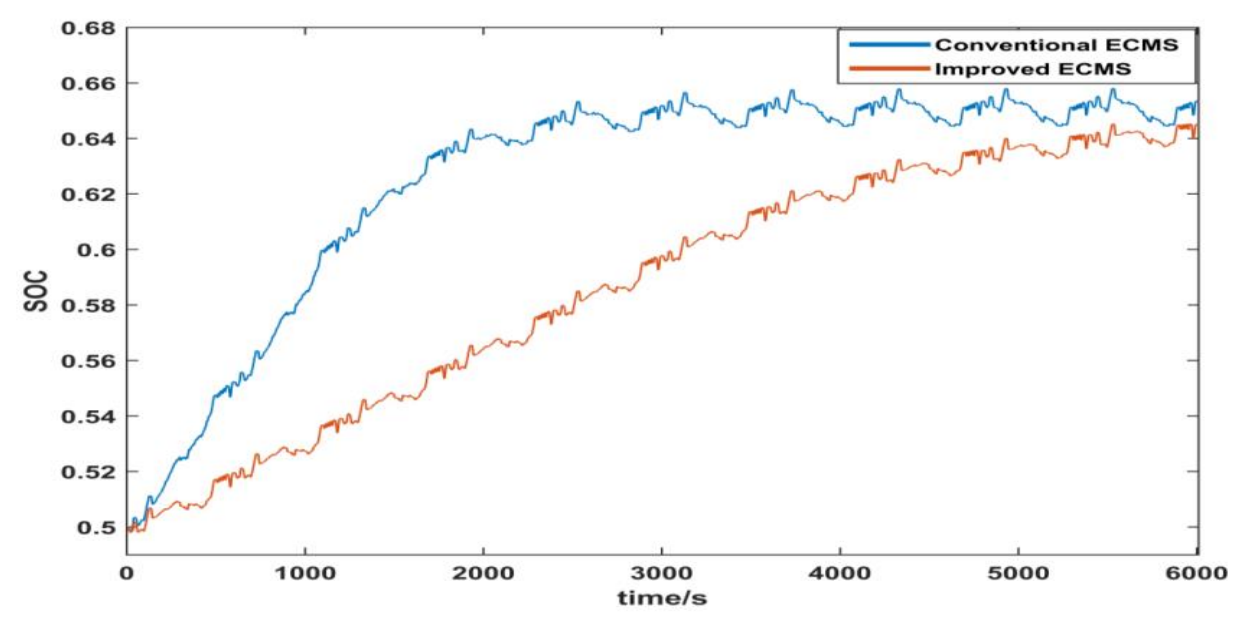

Figure 11. Battery SOC.
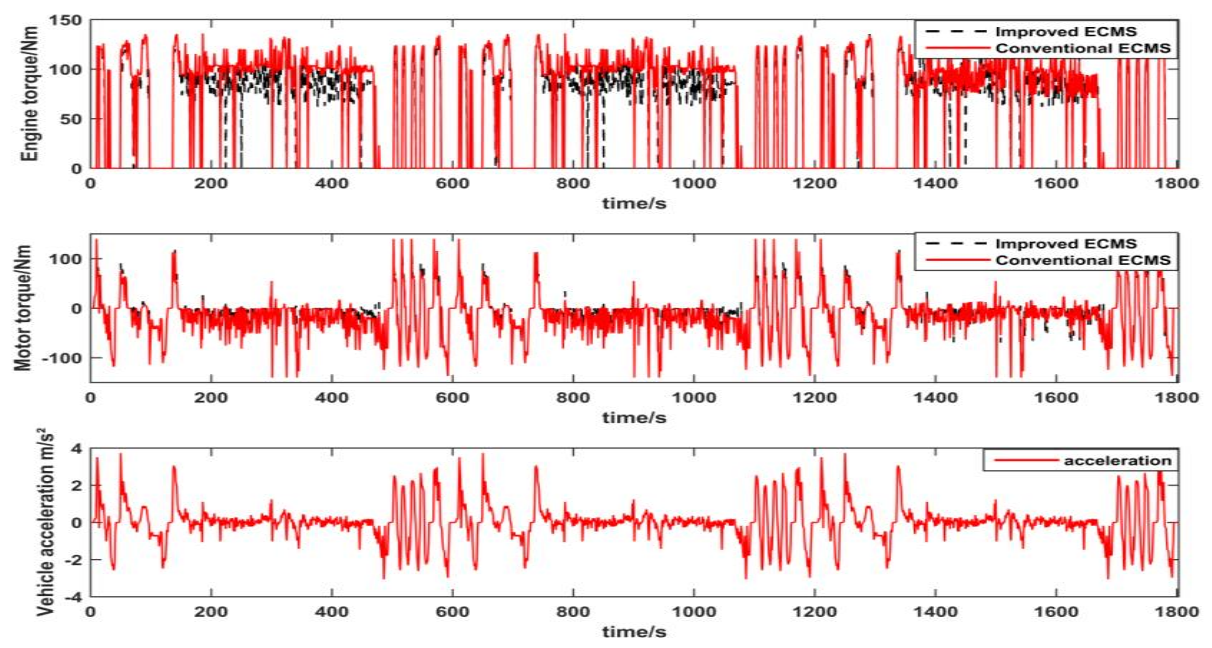

Figure 12. Engine and motor torque.

Figure 13 shows the comparison of the engine efficiency between the improved and conventional ECMS. The optimum operating point efficiency of the engine selected in this study is 0.3 . In the early stage of the cycle, the conventional ECMS has relatively high engine output torque and working point 
load, most of which is near the external characteristic curve and the proportion of low efficiency zones is relatively high. These two reasons increase the fuel consumption of the vehicle. Under the improved ECMS, when the engine efficiency deviates from the high efficiency zone, the motor can assist the engine to drive the whole vehicle, which helps the engine operating point efficiency remain above 0.25 and reduce the engine load at the same time. Figures 12 and 14 show that the improved ECMS motor generates a larger torque when the vehicle is driven at a lower speed than the conventional ECMS motor, and the efficiency is relatively high. Meanwhile, the motor is mostly in the drive mode. However, most of the motor working points under the conventional ECMS are in the power generation mode, which can make the working points of the improved ECMS engine less than that of the conventional ECMS, and it was beneficial to reduce the fuel consumption of the vehicle for the improved ECMS.
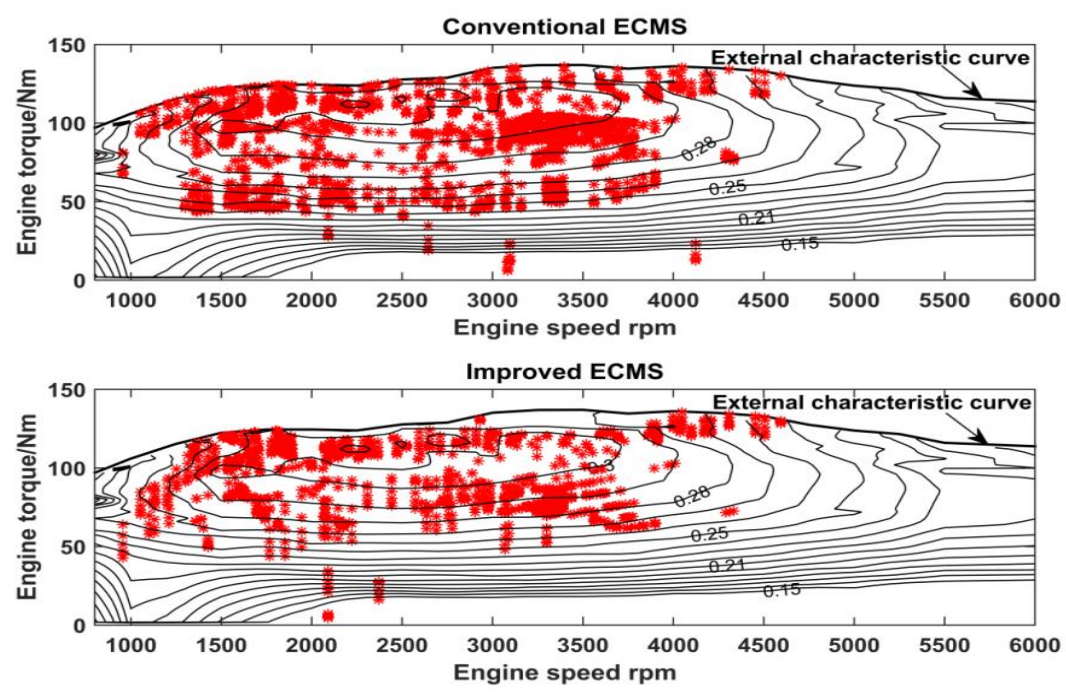

Figure 13. Engine efficiency.

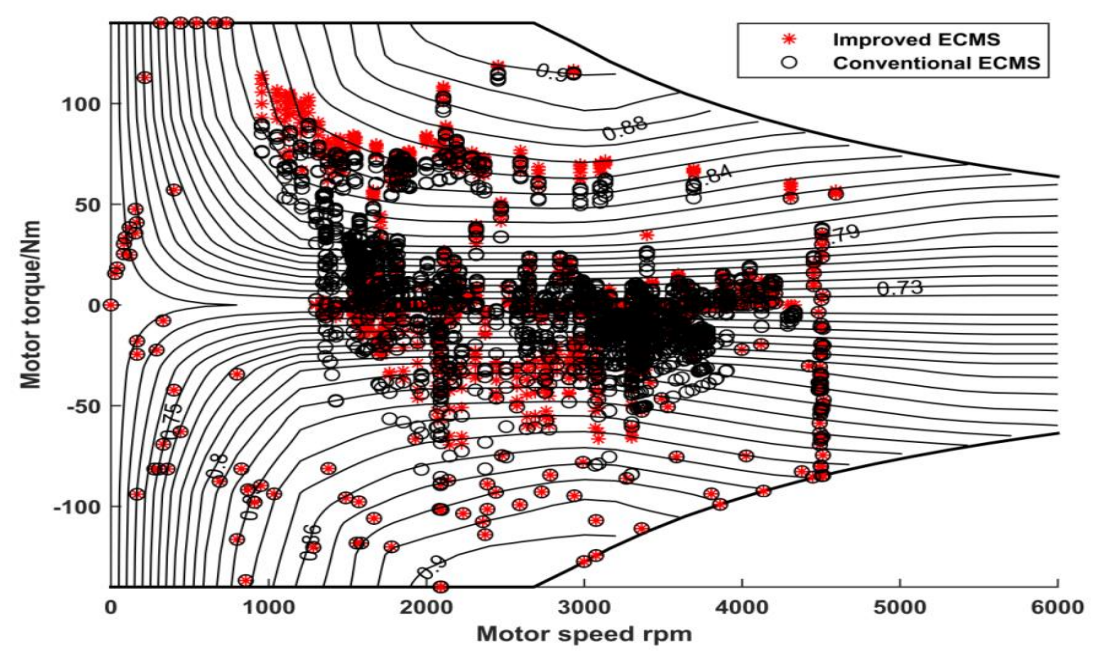

Figure 14. Motor efficiency.

Table 9 shows the comparison of the fuel economy between the improved ECMS, conventional ECMS, and RB control strategies. The data shows that the SOC under the improved ECMS is better maintained near the target value. The equivalent $100 \mathrm{~km}$ fuel consumption is $1.88 \%$ and $10.17 \%$ lower than the conventional ECMS and RB control strategy, respectively. The results verify the effectiveness of the proposed control strategy in this article. 
Table 9. Simulation results of fuel economy.

\begin{tabular}{cccc}
\hline Parameters & Rule-Based & Conventional ECMS & Improved ECMS \\
\hline Equivalent fuel consumption $(\mathrm{L} / 100 \mathrm{~km})$ & 8.6801 & 7.9472 & 7.7975 \\
Initial SOC & 0.5 & 0.5 & 0.5 \\
Final SOC & 0.6458 & 0.6535 & 0.6451 \\
\hline
\end{tabular}

\section{Conclusions}

- A study was conducted to improve the fuel economy of a parallel hybrid electric vehicle using an ECMS with the equivalent factor as the core. The relationship model between acceleration $a$, battery SOC, and equivalent factor $\mathrm{S}$ was established according to the vehicle driving state, and the best equivalent factor MAP was obtained and verified by simulation.

- The simulation results show that compared with conventional ECMS, the proposed ECMS better maintains the SOC of the battery at the end of the driving process and improves fuel economy by $1.88 \%$; compared with the RB energy management strategy, the fuel economy is improved by $10.17 \%$. The results thus confirm the effectiveness of the proposed control strategy.

- A simulation was carried out under the US06 conditions with the initial SOC $=0.5$. Since the establishment of the equivalent factor correction function depends on the acceleration of the vehicle and the battery SOC, the control strategy proposed in this article is still applicable to other driving conditions; meanwhile, this strategy still applies when the initial battery SOC changes. But if the working condition and the initial SOC change, the fuel-saving effect of the vehicle will also change.

- The engine model studied in this paper is a steady-state model obtained by two-dimensional interpolation under steady-state engine conditions. During the whole vehicle driving process, most of the engine operation points were under dynamic conditions. When the vehicle accelerates, the engine torque fluctuation range is large; thus, the next step is to compare the fuel economy effect according to the engine dynamics model.

Author Contributions: Conceptualization, X.L.; methodology, X.L.; software, S.W.; validation, X.L.; formal analysis, S.W.; investigation, X.L.; resources, D.Q.; data curation, X.L.; writing-original draft preparation, X.L.; writing-review and editing, D.Q.; visualization, S.W.; supervision, D.Q.; project administration, D.Q.; funding acquisition, D.Q.

Funding: This research was funded by the National Key Research and Development Program of China (No. 2016YFB0101402).

Conflicts of Interest: The authors declare no conflict of interest.

\section{References}

1. Yi, T. Real-time simulation and research on control algorithm of parallel hybrid electric vehicle. Chin. J. Mech. Eng. 2003, 39, 156-161.

2. Wirasingha, S.G.; Emadi, A. Classification and Review of Control Strategies for Plug-In Hybrid Electric Vehicles. IEEE Trans. Veh. Technol. 2011, 60, 111-122. [CrossRef]

3. Bianchi, D.; Rolando, L.; Serrao, L.; Onori, S. A Rule-Based Strategy for a Series/Parallel Hybrid Electric Vehicle: An Approach Based on Dynamic Programming. In Proceedings of the 3rd Annual Dynamic Systems and Control Conference, Cambridge, MA, USA, 13-15 September 2010; pp. 507-514.

4. Zhu, H.; Yongfa, Q.; Sun, H.; Chao, Y.; Lin, Z. Research of energy management strategy in PHEV based on fuzzy control. Agric. Equip. Technol. 2016, 42, 62-64.

5. Chen, Z.; Mi, C.C.; Xu, J.; Gong, X. Energy Management for a Power-Split Plug-in Hybrid Electric Vehicle Based on Dynamic Programming and Neural Networks. IEEE Trans. Veh. Technol. 2014, 63, 1567-1580. [CrossRef]

6. Qin, D.; Yang, G.; Liu, Y.; Lin, Y. A research on energy consumption optimization control strategy for plug-in hybrid electric vehicle. Automot. Eng. 2015, 37, 1366-1377. 
7. Park, J. Development of equivalent fuel consumption minimization strategy for hybrid electric vehicles. Int. J. Automot. Technol. 2012, 13, 835-843. [CrossRef]

8. Paganelli, G.; Delprat, S.; Guerra, T.M. Equivalent Consumption Minimization Strategy for Parallel Hybrid Powertrains. In Proceedings of the 55th IEEE Vehicular Technology Conference, Birmingham, AL, USA, 6-9 May 2002; pp. 2076-2081.

9. Hosseini, S.M.; Carli, R.; Dotoli, M. Model Predictive Control for Real-Time Residential Energy Scheduling under Uncertainties. In Proceedings of the IEEE International Conference on Systems, Man, and Cybernetics, IEEE Syst Man \& Cybernet Soc (SMC), Miyazaki, Japan, 7-10 October 2018; pp. 1386-1391.

10. Lin, X.; Feng, Q.; Zhang, S. Global Optimal Discrete Equivalent Factor of Equivalent Fuel Consumption Minimization Strategy Based Energy Management Strategy for a Series-parallel Plug-in Hybrid Electric Vehicle. Chin. J. Mech. Eng. 2016, 52, 102-110. [CrossRef]

11. Larsson, V.; Johannesson, L.M.; Egardt, B.; Lassson, A. Benefit of Route Recognition in Energy Management of Plug-in Hybrid Electric Vehicles. In Proceedings of the American Control Conference (ACC), Montreal, QC, Canada, 27-29 June 2012; pp. 1314-1320.

12. Hongfei, H.; Xiangdong, H.; Amp, L.Y. Real-time Equivalent Energy Consumption Minimization Strategy for HEV. Automot. Eng. 2006, 28, 516-520.

13. Qin, S.; Duoyang, Q.; Bing, W. A Research on Equivalent Fuel Consumption Minimization Strategy Optimization Based on Double-loop Multi-objective Particle Swarm Optimization Algorithm. Automot. Eng. 2018, 40, 1005-1013.

14. Lin, X.Y.; Sun, D.Y. Driving Pattern Recognition Based on ECMS and its Application to Control Strategy for a Series-parallel Hybrid Electric Bus. J. Hunan. Univ: Nat. Sci. Ed. 2012, 39, 43-49.

15. Ying, W. Study on Energy-saving Driving Skills of City Bus. J. Trans. Eng. Info. 2013, 11, 114-120.

16. Xiang, C.; Ding, F.; Wang, W. Energy management of a dual-mode power-split hybrid electric vehicle based on velocity prediction and nonlinear model predictive control. Appl. Energy 2017, 189, 640-653. [CrossRef]

17. Carli, R.; Dotoli, M. Energy Scheduling of a Smart Home Under Nonlinear Pricing. In Proceedings of the 53rd IEEE Annual Conference on Decision and Control (CDC), Los Angeles, CA, USA, 15-17 December 2014; pp. 5648-5653.

18. Krein, P.T. Battery Management for Maximum Performance in Plug-In Electric and Hybrid Vehicles. In Proceedings of the IEEE Vehicle Power and Propulsion Conference (VPPC), Arlington, TX, USA, 9-12 September 2007; pp. 2-5.

19. Gökce, K.; Ozdemir, A. An instantaneous optimization strategy based on efficiency maps for internal combustion engine/battery hybrid vehicles. Energy Convers. Manag. 2014, 81, 255-269. [CrossRef]

20. Wang, Q.; You, S.; Li, L. Survey on Energy Management Strategy for Plug-in Hybrid Electric Vehicles. Chin. J. Mech. Eng. 2017, 53, 1-19. [CrossRef]

21. Paganelli, G.; Ercole, G.; Brahma, A. General supervisory control policy for the energy optimization of charge-sustaining hybrid electric vehicles. J.SAE Rev. 2001, 22, 511-518. [CrossRef]

22. Sun, C.; Sun, F.; He, H. Investigating adaptive ECMS with velocity forecast ability for hybrid electric vehicles. Appl. Energy. 2017, 185, 1644-1653. [CrossRef]

23. Zhao, D.; Stobart, R.; Dong, G.; Winward, E. Real-Time Energy Management for Diesel Heavy Duty Hybrid Electric Vehicles. IEEE Trans. Contr. Syst. Technol. 2015, 23, 829-841. [CrossRef]

24. Gong, Q.; Li, Y.; Peng, Z.R. Trip-Based Optimal Power Management of Plug-in Hybrid Electric Vehicles. Trans. Veh. Technol. 2008, 57, 3393-3401. [CrossRef]

(C) 2019 by the authors. Licensee MDPI, Basel, Switzerland. This article is an open access article distributed under the terms and conditions of the Creative Commons Attribution (CC BY) license (http://creativecommons.org/licenses/by/4.0/). 